\title{
Cultural Psychology, A New Look: Reply to Bond (2002), Fiske (2002), Kitayama (2002), and Miller (2002)
}

\author{
Daphna Oyserman \\ University of Michigan
}

\author{
Markus Kemmelmeier \\ University of Nevada
}

\author{
Heather M. Coon \\ North Central College
}

\begin{abstract}
M. H. Bond (2002), A. P. Fiske (2002), S. Kitayama (2002), and J. G. Miller (2002) joined D. Oyserman, H. M. Coon, and M. Kemmelmeier (2002) in highlighting limitations of the individualism-collectivism model of culture. Concern is warranted; nevertheless, individualism-collectivism helps structure discourse on the influence of culture on the mind. To avoid level-of-analysis entanglements, Oyserman et al. propose an integrative model that includes distal, proximal; and situated cultural features of societies and internalized models of these features, highlights the importance of subjective construal, and uses evolutionary perspectives to clarify the basic problems cultures address. Framed this way, it is clear that, depending on situational requirements, both individualism- and collectivism-focused strategies are adaptive; thus, it is likely that human minds have adapted to think both ways.
\end{abstract}

That societies, cultures, and nations differ in many subtle and not-so-subtle ways is well known. Moreover, some of these differences are historical rather than current and some of these differences are more central than others. Travelogues, comedy routines, and business guides built on differences in the understanding of time, norms for politeness, and other elements of everyday life are perennial favorites. What is less clear, though, is the extent to which differences between nations, societies, cultures, and ethnic and other groups can be modeled and systematized to make predictions about how culture can systematically influence cognition, affect, and motivation. That is, Are some of the ways that, say, Americans and Chinese differ applicable to ways in which Americans and Indians differ or the ways in which Germans and Nigerians differ? Although it is of interest to understand a specific culture at a certain time and place, this is not the central goal of cultural psychology. Rather, the essential goal of the field is to understand how culture influences how the mind works and to identify cultural contingencies that moderate general processes of human cognition, affect, and behavior. To take on this challenge, cultural psychologists must posit general principles that are likely to have different instantiations across cultures and are likely to have impact on human cognition, affect, and behavior.

Daphna Oyserman, Institute for Social Research. University of Michigan; Markus Kemmelmeier, Department of Sociology, University of Nevada; Heather M. Coon, Department of Psychology, North Central College.

This article benefited from discussion with Norbert Schwarz and the Culture and Self lab group at Stanford University.

Correspondence concerning this article should be addressed to Daphna Oyserman, Institute for Social Research, Unjversity of Michigan, 426 Thompson Avenue, Ann Arbor, Michigan 48106-1248. E-mail: daphna.oyserman @umich.edu
In response to our (Oyserman, Coon, \& Kemmelmeier, 2002) review of the literature on individualism and collectivism, Bond (2002), Fiske (2002), Kitayama (2002), and Miller (2002) each highlight the limitations of the current body of empirical evidence. We agree with many of the points the commentaries raise and note that these concerns are shared by many well-known voices in the field (e.g., Kagitcibasi, 1997; Kashima, Yamaguchi, Kim, Choi, Gelfand, \& Yuki, 1995; Triandis, 1995, 1996). First, we agree that individualism and collectivism do not replace the study of culture; specific, local phenomena should be studied and have a place within cultural psychology. Rich, detailed descriptions of particular groups, societies, and situations can be invaluable at the hypothesis generation of any research program. Second, the terms individualism and collectivism have become somewhat bloated: they are too broadly construed and are often used to explain almost any cultural or cross-cultural difference. Third, it is not useful to tie individualism and collectivism too closely to particular, opposing, articulated value systems. Finally, cultural psychologists should not abandon the search for other promising general or foundational cultural schemas.

Nevertheless, we disagree with the gist of the commentators' conclusions. Despite the simplifications and flaws in the current body of research, some relevant insights have been gained. Rather than abandon the individualism-collectivism constructs, we propose that individualism and collectivism are helpful in describing particular ways in which cultures can differ systematically. The individualism-collectivism constructs are helpful general models of one active ingredient, or means by which culture influences not only what we think but also how we think. Individualism and collectivism can be helpful if thought of as general cultural metaschemas or foundational schemas-generalized, abstracted ways of making meaning - rather than as a specific list of articulated values or a specific set of content-rich cultural scripts. Rich de- 
scriptions (of practices, situations, institutions) are less likely to provide useful general models of the powerful moderating effects of culture on the mind without some organizing framework.

Individualism and collectivism, understood as empirically and theoretically based models of culture, do provide a way of making predictions across groups, time, place, and the trappings of a specific situation. They do so by centralizing commonalities in the subjective construal of situations. Our review (Oyserman et al., 2002) documented that individualism and collectivism have served as useful models, providing insight into systematic differences in values, ways of thinking, ways of relating to others, ways of being a self, and bases of well-being. We summarize these insights in the first section of this response. Abandoning individualism and collectivism as a way of modeling culture would be a mistake, throwing out the structural baby with the muddy bath water of current research.

Nevertheless, we agree with the commentators that a reorientation in the focus of cultural psychology is needed. In the second section of the article, we provide a general framework or rubric of cultural psychology research. This general schematic framework integrates the assumptions made by previous and ongoing research in the field in a way that clarifies how the various approaches emerging in the research literature are associated. It provides a springboard for our outline of the future of cultural psychology. In our view, reorientation of the field should not follow the suggestions offered by the commentators. Instead, it should focus on understanding process. We address this need and illustrate it with some recent experimental results, drawing on work from our own lab.

\section{What Has Been Learned}

\section{Points of Departure}

A major thrust of cultural psychology in the past 20 years has been based on modeling culture in terms of differences across groups in levels of individualism and collectivism. We began our reexamination of the literature on individualism and collectivism (Oyserman et al., 2002) with a focus on the intellectual contribution of Hofstede (1980), who distinguished individualismcollectivism (along with power distance, uncertainty avoidance, and masculinity-femininity) as a core way to model cultures. Hofstede deduced these cultural constructs through factor analyses of responses to a work-values survey and an integration of these responses with a large-scale review of historical, structural, geographic, and economic differences between the nations in his sample.

Hofstede's (1980) achievement was in distilling a general frame for making sense of cultures, not necessarily in the measure he used to rank countries on individualism and collectivism. As noted in our review (Oyserman et al., 2002; and emphasized by Bond, 2002), what Hofstede actually measured as individualismcollectivism does not bear much resemblance to what he and other cultural psychologists generally have taken individualism, and especially collectivism, to mean. Interest lies in the social structures, social practices, social situations, social norms and scripts likely to emerge in societies differing in individualism and collectivism, and the implications of individualism and collectivism for cognition, affect, and emotion. Perhaps it is not surprising that few researchers have used Hofstede's measure in their own research.
Other problems in the application of the individualismcollectivism model abound. First, as noted in all comments (and especially Bond, 2002, and Kitayama, 2002), there is a disjuncture between individual-level endorsement of values on a value scale and analyses of cultural systems. Second, from the beginning it has been clear that individualism-collectivism, though an important way of organizing models of cultural influence, is neither the only model nor a homogeneous description of cultural frames. As reviewed by Miller (2002), Triandis outlined additional axes that may interface with individualism or collectivism. Perhaps most important is individualism-collectivism's overlap with power distance (Hofstede, 1980). Social groups differ not only in the extent to which they focus attention on individual or collective values and goals but also in the extent to which differences in power, authority, and status are accepted as legitimate. Third, the connection between individualism and collectivism as shorthand descriptions of social institutions, everyday practices, personal beliefs, behaviors, and cognitive processes has not been sufficiently researched. Last, the initial framing of individualism and collectivism as opposing social frameworks left a residue of dichotomizing in the field's theorizing about these cultural models-as if social institutions, practices, and situations created fixed cultural minds that make sense of the world through either an individualistic or a collectivistic lens.

In spite of these limitations, we focused specifically on individualism and collectivism in our review (Oyserman et al., 2002), both because these constructs have received the most research attention as models of cultural difference and because they have appeal as basic processes. The bulk of current research either focuses on assessments of individualism and collectivism as value or attitude statements or on assessments of differences in selfconcept, well-being, relationships, or cognition as a way to infer effects of individualism and collectivism. We reviewed the literature in both of these domains. In spite of the complications and error introduced by simplistic models and the common practice of defining culture as responses to a value scale, this body of research, taken as a whole, is important. Individualism-collectivism as a model of culture does provide a way of making specific predictions about how the mind works that can be generalized across superficial differences-in groups, time, place, and situations-and highlights powerful commonalities in the subjective construal of tasks and situations.

Moreover, by comparing responses of American college students to college students from another wealthy, technologically advanced country, primarily Japan, cultural psychologists using Hofstede's (1980) framework as a springboard capitalized on cross-national comparisons to deduce general cultural patterns. There are obvious weaknesses in a research paradigm that assumes that Americans and Japanese differ in individualism and collectivism and then uses differences between these specific countries to claim that all groups differing in individualism and collectivism share these differences. Nevertheless, this paradigm was useful for at least two reasons. First, the comparison of two advanced industrial countries freed cultural psychology from the stumbling block of culture as a developmental process in which some cultures are linked to higher stages of development than are others. It therefore allowed for analyses of the ways that individualism and collectivism could differ without a presumed value judgment that one cultural system (often individualism) was better or more advanced 
than the other cultural system (often collectivism). Second, it linked concerns of cultural psychologists to the concerns of psychology as a whole by comparing the minds of American undergraduates to the minds of other equally well-educated undergraduates who appeared not to think the same way. This empowered cultural psychologists in their mission to broaden the framework of social science research from understanding the minds of American middle-class college students to understanding the mind more generally.

\section{Patterns of Difference}

Despite many flaws and limitations in the body of research, our review indicates that individualism and collectivism are useful models. With regard to articulated values, European Americans are higher in individualism and lower in collectivism than others, particularly non-Westerners, with a number of caveats. African Americans are reliably higher in individualism than are European Americans (and not higher in collectivism). Latin Americans (in Latin America or the United States) tend to be higher in both collectivism and individualism than European Americans, and Japanese are not higher in collectivism and differ from European Americans in individualism in subtle ways not yet well understood. Similar concerns are true for the assumption that Koreans are higher in collectivism than Americans. Not enough research has focused on the Middle East and Africa, in spite of effect sizes that are at least as large as are those for the more frequently studied Asians and East Asians.

In addition to attempts to classify groups in terms of levels of individualism and collectivism, cultural researchers have asked the following questions: Is individualism associated with different cognitive styles and ways of relating to others than collectivism? Do individualists make sense of themselves and their lives differently than collectivists? Unfortunately, much of the cross-national research merely assumes stable between-groups differences, often at odds with the available evidence, and fails to isolate individualism-collectivism as the crucial ingredient for any observed differences. Yet an emerging body of experimental research indicates that individualism-collectivism does indeed exert a causal influence on cognition and behavior.

Relationality. Research on relationality is broad in scope, befitting its centrality in distinguishing individualism and collectivism. Evidence suggests systematic differences in whether in- and out-group members are treated differently and whether equity- or equality-based rewards are assumed to motivate better performance, among other differences that map well onto individualism and collectivism. An important caveat made clear in this research is that individualism and collectivism should not be reduced to a social versus asocial dichotomy. Individualists are social; they turn to others for support and acceptance and feel close to family members. Individualists and collectivists differ in the kinds of sociability they prefer, the meaning of social interactions, and their beliefs about important groups. Individualism frames even important group memberships as temporary and voluntary, whereas collectivism is characterized by the belief that fitting into groups is an important, inevitable part of being human. Furthermore, this research also emphasizes that family focus and collectivism should be separated in future work. When situations are construed as both family focused and individualistic, we would postulate a different psychological response than when situations are construed as both family focused and collectivistic. We view this research as having important consequences both for broadening research on social cognition and for fields such as business and political science. Clearly, if deals are to be negotiated, businesses run, peace treaties kept, and conflicts avoided, then the consequences of different subjective construals of the meanings of social contact and interchange must be taken into account (see, e.g., Oyserman \& Lauffer, in press).

Cognitive differences. With regard to cognitive differences, most of the research base involves comparisons between China and the United States (although some replication within the United States with individuals differing in their self-rating of individualism was found and some research focuses on comparisons of India or Korea with the United States). Chinese are less likely to ignore context, more likely to think in terms of systems or wholes, and more likely to be persuaded by group-focused rather than individual-focused appeals.

Self-concept and well-being. With regard to self-concept and well-being, we found some research assuming simplistic dichotomies, for example, that countries higher in individualism have more well-being in the populace or that individuals high in individualism have higher self-esteem, in the simple sense of feeling better about themselves. Results from this research are difficult to interpret because a more careful read of the individualism and collectivism constructs would be to say that individualism and collectivism carry with them different contingencies or bases for making sense of the self and life in general. Kitayama (2002) reviewed research focused on differences in how the self is evaluated, contrasting a goal of liking and feeling good about oneself with a goal of improving oneself.

Thus, previous research on individualism and collectivism, although limited by a focus on culture as articulated values and an overly simple view of the likely effects of individualism and collectivism on self-concept, well-being, relationality, and cognition, has shown important differences. Rather than abandoning the terms, we call for more careful analyses of process, using experimental manipulations of accessibility of individualistic versus collectivistic worldviews.

\section{Reorienting Cultural Psychology: What Is Needed?}

Research within the individualism-collectivism model has contributed to a growing awareness that culture must be taken into account if psychologists are to understand systematic differences in how the mind works and how this influences cognition, affect, and motivation. That is not to say that research to date is without flaw. Much of this research seems fueled mostly by the desire to document that "culture" does matter. As we already noted, a common research strategy is simply to select countries assumed to differ in individualism and collectivism and to attribute any emerging differences on the dependent variables to differences in individualism and collectivism. This approach assumes that differences in individualism and collectivism hold for all groups within a country and are relatively independent of specific situations. Unfortunately, countries and cultures differ in more than their level of individualism-collectivism, rendering this approach fraught with innumerable, and mostly unknown, confounds and leaving 
open the question of which social structures or social institutions are similar enough across otherwise very different societies to create similarities in individualism and collectivism. In essence, this approach ignores altogether concerns about process and level of analysis.

However, researchers interested in culture do not always ignore process or level of analysis and it is possible to outline a number of approaches that do attempt to make sense of process. To facilitate an overview, we provide a schematic diagram of how culture has been approached within psychology (Figure 1), moving from more distal, external, and system-based approaches to more proximal, situated, and construal-based approaches. Our goal in drawing this figure is not to suggest that no other ways of construing culture exist but rather to provide a way of integrating the disparate ways in which culture and its impact on cognition, affect, and behavior have been conceptualized. Distal, individual-level, proximal, and situated approaches to modeling and studying culture share in common the assumption that culture is an external quantity "out there" in the social world, within which individuals live their lives and as a result of which they internalize values, attitudes, and norms.

These approaches are credible and fit well with anthropological and other social science perspectives. However, because psychol- ogists assume that it is the sense made of the situation, not the situation itself that is critical, these approaches remain unsatisfactory to the extent that subjective construal of the situation at hand is not experimentally manipulated. This suggests a fifth approach that focuses not on the features of situations but on the culturalladen ways in which situations are construed-the subjective meaning they have for individuals. This approach integrates cultural psychology with social cognition by arguing that culture matters because it influences subjective construal of situations, and it is these subjective construals that should be the focus of our attention.

The connection between subjectively construed situations and cognition, affect, and behavior is in bold print in Figure 1 because we see this as the main way that cultural psychology can provide insight on the influence of culture on how the mind works. Moreover, although not yet integrated into cultural psychology, we see evolutionary psychology as a potentially rich source of hypotheses about the ways culture matters for how the mind works. Hence, we add this level to the model on the bottom, using thinner arrows to denote that evolutionary pressures do not cause culture, although they may set parameters for its likely expression.

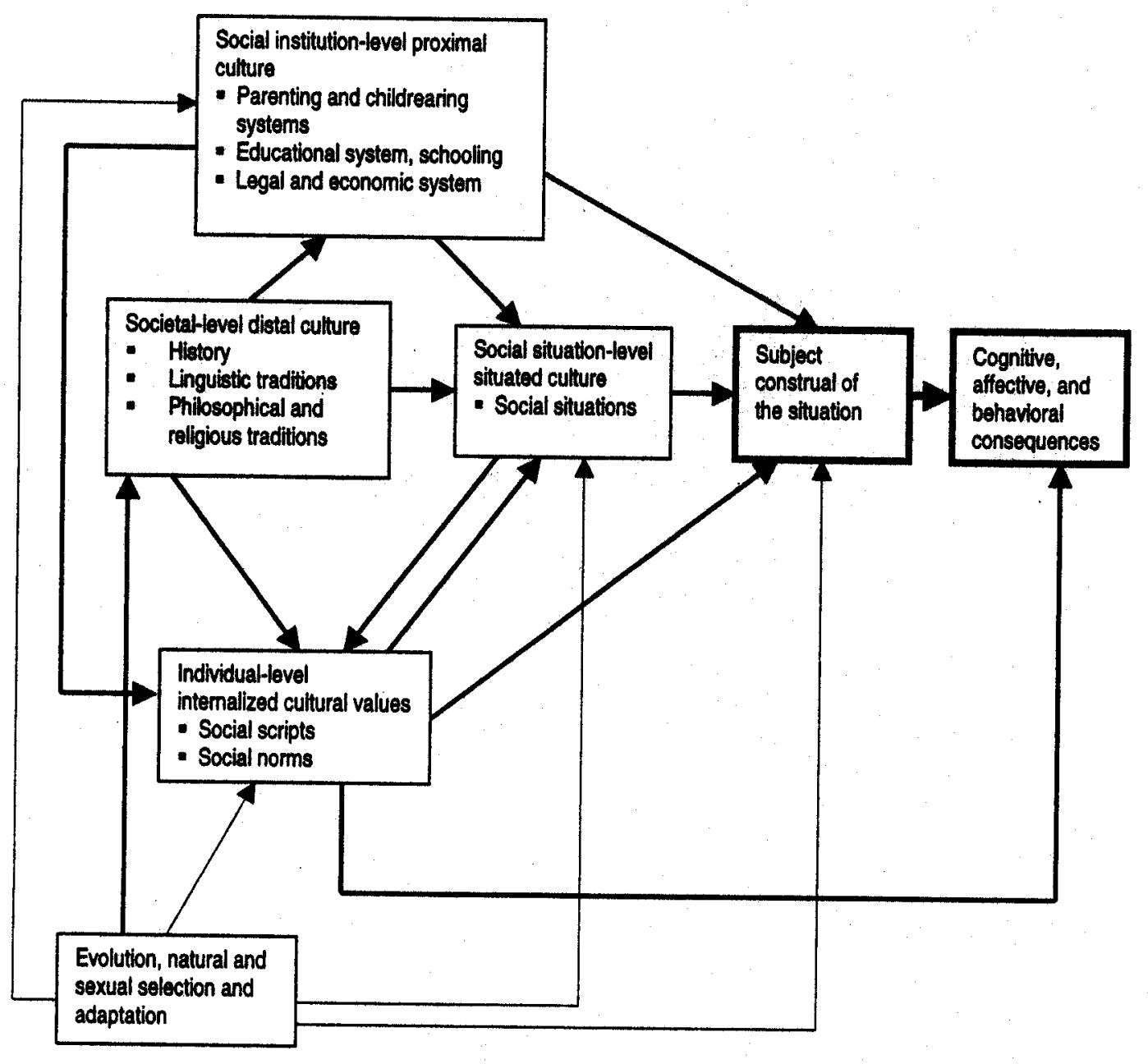

Figure 1 . A socially contextualized model of cultural influences. Bold print connotes the critical connection between subjective construal and culture's consequences. Narrow lines linking evolution and natural selection to culture connote lack of causal argument. 


\section{Distal Approaches to Culture}

We have labeled as distal approaches that look for culture-laden products such as language, history, and religious and philosophical traditions, which differ systematically across societies and are likely to influence current cognition, affect, and behavior. We used the term distal to describe this level of analysis for several reasons. First, the cultural products of interest clearly exist prior to the individual cultural participant. Second, they are assumed relatively stable (albeit not necessarily static) and third, they are likely to influence the nature of other social institutions within which individuals are embedded, as well as characteristics of everyday situations that individuals encounter. These institutions and situations themselves are also viewed as culture laden.

Individualism as a worldview has been associated with Western religious, historical, political, and economic traditions and is assumed to influence values, structure and content of the self, bases of well-being, types of relationships formed, and cognition and judgment. The assumption has been that collectivism is associated with non-Western religious, historical, political, and economic traditions, with corresponding influences. These are distal cultural markers because even though current language use or religious practice may change or be influenced by a particular member of a society, the net effect of these changes will be miniscule compared with the scope of these as markers of the past.

As noted in our review (Oyserman et al., 2002) and all the comments (Bond, 2002; Fiske, 2002; Kitayama, 2002; Miller, 2002), societies do differ in their histories, religions, and political and economic traditions, and these differences do sometimes map in meaningful ways onto cognition, affect, and behavior. However, a shorthand dichotomy of all things Western versus all things non-Western is clearly untenable. Although it was often accepted in early research, the empirical evidence is not supportive of this perspective. A simple example will suffice: Americans are assumed to be both cultural individualists and highly communitarian in orientation at the same time that multiple essays are being written bemoaning the demise of various forms of individualism such as when rugged individualism gave way to the company man.

Cultures always provide insight into how to be a person in the world, what makes for a good life, how to interact with others, and which aspects of situations require attention and processing capacity. Cultures, in fact, provide more than one answer to these questions, but the answers may well be weighted toward either individual or collective foci. To bridge the logical leap required to go from distal cultural features to current cognition, affect, and behavior, cultural psychologists must assume that distal culture (e.g., a society's linguistic tradition, philosophy, religion, teachings, and ideology) instills a chronically accessible focus of attention that molds subjective construal of situations. In its most simple form, this would lead to differences in Chinese and American minds.

Yet, a distal perspective on culture does not require that individuals are either individualistic or collectivistic in their mindset because, even at this level of analysis, societies clearly have features of both individualism and collectivism. An example from anthropology comes from Shore's (1996) description of Micronesian models of space. He convincingly showed that the Micronesian language allows articulation of both relational and abstract organization of space, depending on the need, although relational organization is the more automatic and fluid response. Abstract organization, what he terms the God's eye-view, removes the person, whereas typical organization embeds the person in the context.

\section{Individual-Level Approaches to Culture}

We have labeled as individual-level approaches that assume that at least part of what culture is can be found at the individual level as articulated mental representations. These approaches treat culture as a set of internalized values, attitudes, scripts, and norms that are likely to influence cognition, affect, and motivation in meaningful ways. That values would be one of the consequences of culture makes sense. Values are internalized cognitive structures that guide choices by evoking a sense of basic principles of right and wrong (e.g., moral values), as well as priorities (e.g., personal achievement vs. group good). Values can be studied at the individual level like other cognitive concepts, but are also amenable to social- or group-level analyses, in terms of the norms, priorities and guidelines set up by societies, cultures, and other social groupings. When mobilized or made salient, individual values are linked with behavior and choices. Cultures may be said to provide concrete and social embodiments of values (Oyserman, in press).

Indeed, a common approach to studying culture is to obtain ratings of individualism and collectivism by asking participants to fill out value scales, thus avoiding the pitfalls of merely assuming differences in individualism and collectivism. To study cultural effects by correlating responses to individualism-collectivism scales with responses to self-concept, well-being, relationality, or cognition tasks or measures, researchers must assume that culture can reasonably be expressed as a set of explicit, articulated values, attitudes, and beliefs and that standard scales can capture these beliefs. It is not impossible to assume that average values differ cross-culturally, and indeed, early research documents some average differences. This approach shares the strengths and weaknesses of individual difference research in the personality tradition. Most important, differences in individualism and collectivism are likely to be confounded with numerous other and, largely unknown, individual differences. As a result, this approach may document that people differ without providing much insight into the specific processes underlying the observed differences.

Moreover, there are numerous well-documented difficulties in comparing responses to attitude or value scales across cultures. We summarized these issues in our review (Oyserman et al., 2002); they are also addressed in Kitayama's (2002) commentary and by Triandis (1995). Briefly, when vague quantifiers anchor responses, respondents must infer what $a$ lot or very much agree means and can only do so within the context of their culture. One possible way to handle this limitation is to ask respondents to report on their behaviors (inferring attitudes and values from behavior) rather than report on their attitudes or values directly. Of course, selfreport of behavior is limited by quite similar problems; even apparently simple behavioral questions pose complex cognitive tasks, and self-reports are highly context dependent. Minor changes in question wording, format, or order can profoundly affect the obtained results. Hence, how researchers ask questions about individualism and collectivism can dramatically influence the answers they receive. 
In its most simple form, an individual-level analysis of culture would lead to the assumption that individuals were high either in individualism or collectivism. This simple description is neither supported by the empirical literature nor is it a necessary consequence of the model. In fact, there is no reason to assume that individuals hold only one set of values, norms, and scripts and apply them no matter what. It seems reasonable to assume that all societies socialize for both individualism and collectivism but differ in the likelihood that one or another of these systems will be triggered (e.g., Oyserman, 1993). However, this approach still leaves open questions about how chronically accessible or situationally cued concepts influence subjective construals of situations.

\section{Proximal-Level Approaches to Culture}

An alternative approach, drawn in Figure 1 to the right of the distal approach, is to look for culture-laden systems such as parenting and child-rearing systems, educational systems, and legal and economic systems. These systems are likely to influence current cognition, affect, and behavior and are themselves at least somewhat proximal in that they may be dramatically changed during the lifetime of individual cultural participants. Rather than being thought of in terms of a society's (distal) history and philosophical traditions, culture can also be thought of as currently instantiated proximal institutions. In this way, societies can be thought to shift toward or away from individualism or collectivism as conditions change (e.g., Kagitcibasi, 1996).

Within this perspective, individualism as a worldview is associated with modernity, democracy, wealth, urbanism, and higher education, as well as parenting and educational systems focused on autonomy and positive self-regard. Collectivism as a worldview is associated with poverty, less education, hierarchical or caste-based societies, and parenting and educational systems focused on selfimprovement, obedience to authority, and acceptance of social structure (e.g., Kagitcibasi, 1997). The influences of modernization, democratization, and wealth are assumed to be key, resulting in the prediction that all countries will shift toward individualism. To afford some control of these factors, cultural researchers are drawn to comparisons of countries that do not differ in modernization, economic system, wealth (e.g., the United States vs. Asian or East Asian countries), or democratic form of government (e.g., the United States vs. Japan or India).

However, because situations and factors such as urbanity and wealth are multiply determined, this research approach is hampered by difficulty teasing apart differences due to individualismcollectivism and differences due to economic, political, or other systemic factors. In spite of these difficulties, research on parenting practices (Kagitcibasi, 1996; also Kitayama, 2002; Miller, 2002) illustrates how these practices frame early life experiences across cultural contexts. Parenting practices influence both objective features of childhood and, more important, the child's subjective construal of the parent's behavior. Socialization patterns and ongoing embeddedness in societies differing in organization are assumed to shape subjective construal of situations in adulthood (whether or not these are mapped onto differences in articulated values).

\section{Culture as Situated}

An emerging body of research attempts to articulate more proximal links between culture and the mind. This situated culture approach highlights the ways social situations differ systematically in terms of their individualistic and collectivistic features. This approach shares many of the classic elements of socialpsychological research and methods in its focus on characteristics of situations and its emphasis on how shifts in situations result in shifts in individual cognition, affect, and motivation. Kitayama (2002) advocated this approach and provided a summary of research using this situation level of analysis.

Rather than attempting to document how history or religiousphilosophical traditions or parenting, educational systems, and economies influence the mind, a situated approach focuses on the everyday situations encountered by individuals. For example, Kitayama (2002) reported that Japanese participants described more self-esteem-decreasing situations than Americans. More important, Japanese participants also reported that American selfesteem-increasing situations would have the same effect on them (see Kitayama, 2002, for a more detailed discussion). In short, this research suggests that cultures differ in features of situations and that these features carry with them certain ways of thinking about the seif.

\section{Culture as Subjective Construal}

The most proximal level of analyses is provided by social cognition approaches that focus on the subjective construal of situations with the goal of showing that systematic manipulations of individualism or collectivism construals influence cognition, affect, and motivation. Priming studies (reviewed by Oyserman et al., 2002), with their social cognition frame, use this level of analysis. All of the previous levels of cultural analysis are compatible with the notion that culture influences the sense we make of social situations-what seems central versus peripheral, what is desirable or valuable, normative or accepted. Furthermore, by increasing accessibility of a particular frame, culture can have online effects on how information is perceived, encoded, processed and remembered, influencing cognition, affect, and behavior.

Rather than assume that situated, proximal, and distal crosscultural differences create either individualistic or collectivistic value systems and subjective construals, we propose that a dichotomized way of thinking about cultures as either individualistic or collectivistic be replaced by the assumption that all societies socialize for both individualistic and collectivistic ways of construing situations. From this perspective, cultures differ primarily in the likelihood that these respective worldviews will be activated. This assumption has important implications for research in this area.

First, if all societies socialize for individualistic as well as collectivistic orientations, instruments that merely assess the endorsement of these orientations are unlikely to capture the crucial differences. Instead, we need measures that assess the likelihood that a given orientation is brought to bear on the subjective construal of different situations. Alternatively, we can explore the impact of individualistic or collectivistic orientations by increasing the temporary accessibility of one or the other through priming manipulations. 
Second, if all indjviduals can think individualistically and collectivistically, it is unlikely that general values-based or crossgroup-based comparisons will yield large between-group differences, independent of the situational context. Unless researchers gain better experimental control over the construal that is applied to a given situation, they will be hard pressed to document the theoretically expected consequences of individualism and collectivism for self-concept, cognition, relationality, and bases of wellbeing. Cultures differ, we speculate, in the number and kind of situations that evoke these construals, not in the consequences of these construals once they are evoked in proximal situations. In spite of the many ways in which cultures differ, the proximal predictor of affective, behavioral, and cognitive responses will be subjective construal of the situation, and subjective construals can be modeled by priming independence-interdependence.

We acknowledge that this perspective may be a departure for some cultural psychologists. Fiske (2002) and Miller (2002) both dismissed the possibility of using priming techniques to study the effects of cultural frame on cognition, affect, and relationality. Fiske (2002) correctly noted that priming would not turn a communal Chinese farmer into a cowboy. We agree. However, the goal of priming is to isolate the causal influence of different subjective construals. Priming allows psychologists to isolate the operation of individualistic or collectivistic orientations in controlled settings. In this way, priming provides researchers with an opportunity to determine the range of thoughts and behaviors affected by the primed orientation rather than by the numerous other variables confounded with the respective orientation under natural conditions (for a related discussion, see Schwarz, 1987). We acknowledge that psychologists' emphasis on understanding processes is at odds with anthropologists' emphasis on understanding cultures. Aithough both efforts are complementary, cultural psychology's goal is to identify cultural contingencies that moderate individuals' thought and behavior, not to provide a rich description of a specific culture, or a communal farmer within a culture.

Of course, individualism and collectivism are not the only cultural axes, and we suspect that issues related to power and the meaning of power are also important parts of these subjective construals, as are judgments as to whether the situation involves family obligations. For cultural psychologists, the important question is, Which aspects of cultural variation have systematic effects on cognition, affect, and behavior?

In our own work we have begun to study this process, using experimental manipulation of self-focus (independence or interdependence) to study subtle shifts in cognition. We have found that priming interdependence increases reliance on a context-sensitive cognitive style. Compared with independence-primed participants, interdependence-primed participants perceive stimuli holistically and show better memory for the contexts in which objects are embedded (Kühnen \& Oyserman, in press). Similarly, we have found that interdependence-primed participants are more sensitive to conversational norms and pay closer attention to the common ground established during a conversation (c.g., Haberstroh, Oyserman, Schwarz, Kühnen, \& Ji, in press). More important, the effects of independence and interdependence priming parallel the differences observed between participants from independent (in this case, Germany) and interdependent (in this case, China) cultures. In fact, German participants primed for interdependence are indistinguishable from Chinese participants in our studies.
In addition, Oyserman (2001) showed that priming influences how participants construe social situations. For example. interdependence-primed participants are more likely than independence-primed participants to assume that others will behave in socially conforming ways. Moreover, independence- and interdependence-primed participants differ in the impressions they form of others who behave in independent or interdependent ways (Oyserman, 2001).

\section{Culture and Evolved Adaptive Processes}

Finally, an evolutionary perspective suggests that societies may differ in some but not all aspects of culture, at whatever level it is defined, because natural and sexual selection focus human activities in systematic ways (Badcock, 2000; Shore, 1996). Evolutionary theorizing emphasizes individual reproductive success and inclusive fitness (i.e., the sum of the individual's own reproductive success and the reproductive success of related others, weighted by the degree of relatedness). It highlights how basic impulses for genetic survival can result in differing social patterns, depending on external contingencies like mobility and material resources.

From this perspective, inclusive fitness benefits from observing one's obligations to the in-group and carefully discriminating in-group from out-group members in contexts characterized by low mobility, large family size, and limited material resources, in which many related others live stably in close proximity. Conversely, inclusive fitness benefits from doing one's own thing and cooperating only on a tit-for-tat basis in contexts characterized by high mobility, small family size, and sufficient material resources, in which few related others live close by. Given their investment in related others, individuals in the low resource, low mobility, and large family size contexts might be expected to be relationally focused, making mental procedures that facilitate relational processing highly adaptive. Given their smaller investment in related others and greater need to impress and compete with others for resources, individuals in high resource, high mobility, and small family size contexts might be expected to be individually focused, making mental procedures that facilitate context-independent processing highly adaptive. That is, they are predicted to be more likely to focus on opportunity costs of engaging in one context versus another, making mental procedures that facilitate comparisons between distinct entities adaptive. Note, however, that inclusive fitness would not be well-served by minds that could not shift strategies when the contingencies shifted. Thus, an evolutionary perspective suggests both the "basicness" of independent and interdependent processing as well as the likelihood that all social systems are inhabited by individuals who can do both and draw on one or the other depending on their immediate context.

\section{References}

Badcock, C. (2000). Evolutionary psychology: A critical introduction. Malden, MA: Blackwell.

Bond, M. H. (2002). Reclaiming the individual from Hofstede's ecological analysis-A 20-year odyssey: Comment on Oyserman et al. (2002). Psychological Bulletin, 128, 73-77.

Fiske, A. P. (2002). Using individualism and collectivism to compare cultures-A critique of the validity and measurement of the constructs: Comment on Oyserman et al. (2002). Psychological Bulletin. 128. $78-88$. 
Hot'stede. G. (1980). Culture's consequences. Beverly Hills, CA: Sage. Haberstroh, S., Oyserman. D., Schwarz, N., Künnen, U., \& Ji, L. (in press). Is the interdependent self a better communicator than the independent self? Self-construal and the observation of conversational norms. Journal of Experimental Sociul Psychology.

Kagitcibasi, C. (1996). Family and human development across cultures: A view from the other side. Mahwah, NJ: Erlbaum.

Kagitcibasi, C. (1997). Individualism and collectivism. In J. W. Berry, M. H. Segall, \& C. Kagitcibasi (Eds.), Handbook of cross-cultural psychology: Vol. 3. Social behavior and applications (pp. 1-49). Boston: Allyn \& Bacon.

Kashima, Y., Yamaguchi, S., Kim, U., Choi, S., Gelfand, M. J., \& Yuki, M. (1995). Culture. gender, and self: A perspective from individualismcollectivism research. Journal of Personality and Social Psychology, 69 , 926-937.

Kitayama, S. (2002). Culture and basic psychological theory-Toward a system view of culture: Comment on Oyserman et al. (2002). Psychological Bulletin, 128, 89-96.

Kühnen, U., \& Oyserman, D. (in press). Does the interdependent self have better memory than the independent self? Self-construal and memory. Journal of Experimental Social Psychology.

Miller, J. G. (2002). Bringing culture to basic psychological theoryBeyond individualism and collectivism: Comment on Oyserman et al. (2002). Psychological Bulletin, 128, 97-109.

Oyserman, D. (1993). The lens of personhood. Journal of Personality and Social Psychology, 65, 993-1009.

Oyserman, D. (2001, March). Culture as salience manipulation: The way you think about yourself influences the way you think. In H. Markus \& G. Adams (Chairs), Cultural dynamics: The role of collective representations in the micro-level construction of reality. Symposium conducted at the meeting of the Society for Personality and Social Psychology, San Antonio, TX

Oyserman. D. (in press). Values, psychological perspectives on. In $\mathbf{N}$. Smelser \& P. Baltes (Series Eds.) \& N. Eisenberg (Vol. Ed.), Developmental, social, personality, and motivational psychology: Vol. 22. International encyclopedia of the social and behuvioral sciences. Oxford, England: Pergamon/Elsevier.

Oyserman, D., Coon. H. M., \& Kemmelmeier, M. (2002). Rethinking individualism and collectivism: Evaluation of theoretical assumptions and meta-analyses. Psychological Bulletin, 128, 3-72.

Oyserman, D., \& Lauffer, A. (in press). Examining the implications of cultural frames on social movements and group action. In L. Newman \& R. Erber (Eds.), What social psychology can tell us about the Holocaust: Understanding the perpetrators of genocide. Oxford, England: Oxford University Press.

Schwarz, N. (1987). Geschlechtsrollenorientierung und die Einstellung zu Gewalt gegen Frauen: Informationsaktivierung als Alternative zu ex post facto-Versuchsplaenen [Sex role orientation and attitudes toward violence against women: Information activation as alternative to ex post facto experimental designs]. Psychologische Rundschau, 38(3), 137144

Shore, B. (1996). Culture in mind: Cognition, culture, and the problem of meaning. New York: Oxford University Press.

Triandis, H. C. (1995). Individualism and collectivism. Boulder, CO: Westview Press.

Triandis H. C. (1996) The psychological measurement of cultural syndromes. American Psychologist, 51, 407-415.

Received August 13, 2001

Revision received August 21, 2001

Accepted August 21, 2001

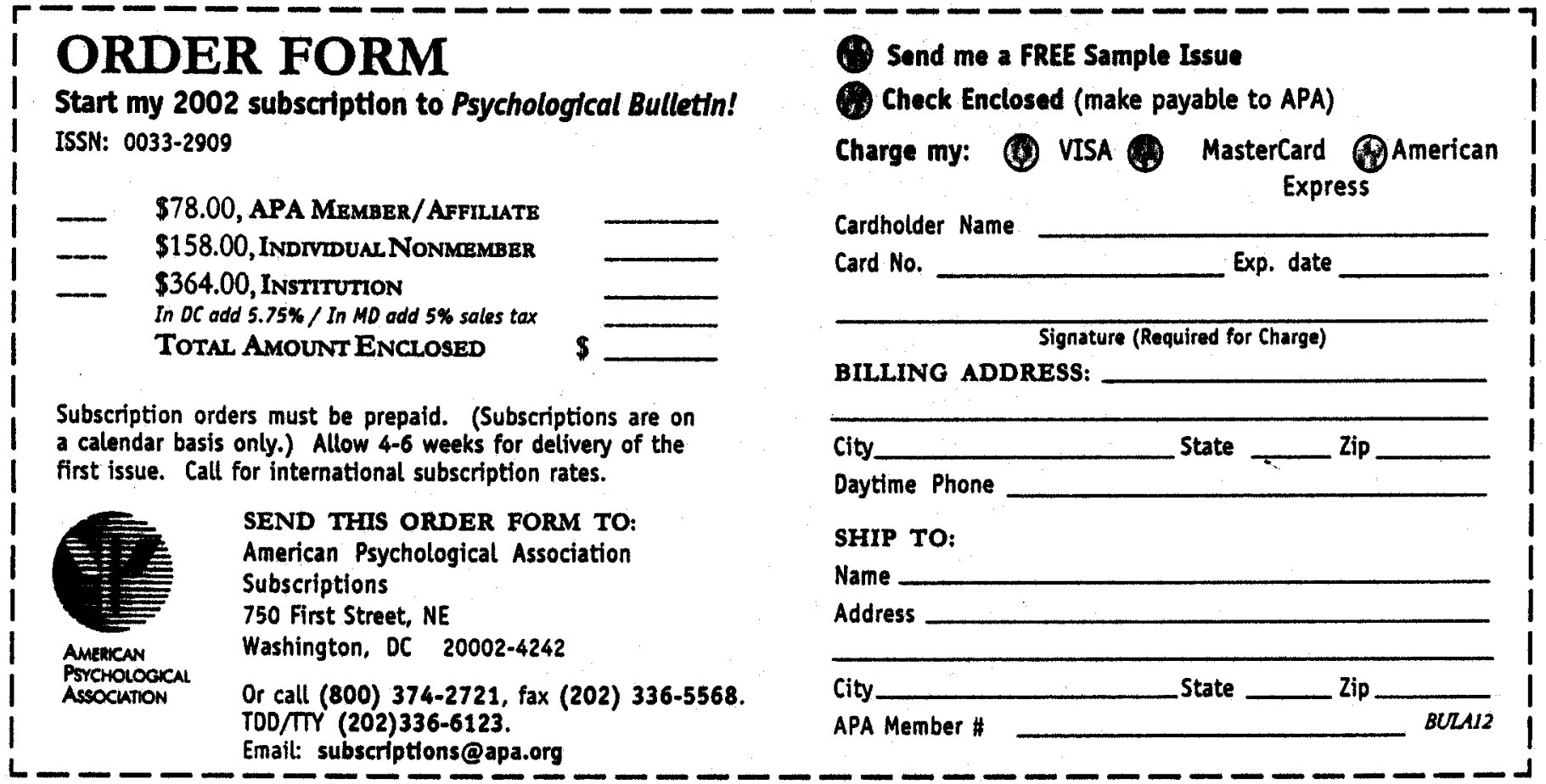

